\title{
Energy mix, technological change, and the environment
}

\author{
Anelí Bongers ${ }^{1}$
}

Received: 21 September 2020 / Accepted: 23 August 2021 / Published online: 4 September 2021

(c) The Author(s) 2021

\begin{abstract}
This paper studies the relationship between the energy mix and the environment using a theoretical framework in which two alternative energy sources are considered: fossil fuels (dirty energy) and renewable energy (clean energy). We find that a positive aggregate productivity shock increases energy consumption and emissions but reduces energy intensity and emissions per unit of output as renewable energy consumption increases, that is, carbon emissions are procyclical but emissions per unit of output are countercyclical. Second, an energy efficiency improvement provokes a "rebound effect" above $100 \%$ (the backfire effect), resulting in a rise of pollutant emissions by increasing energy use. Third, a technological improvement in emissions leads to a reduction in emissions per unit of fossil fuel, but also implies a slow-down in the adoption of renewable energy sources. Finally, we consider the case of a decentralized economy in which the government chooses an optimal specific tax on fossil fuel to maximize social welfare. We show that the "second-best" policy is highly effective in correcting the negative effects of the environmental externality and able to almost achive the centralized economy outcome.
\end{abstract}

Keywords Energy mix · Emissions · Fossil fuels · Renewable energy · Technological change

JEL Classification Q41 $\cdot$ Q42 $\cdot$ Q43 $\cdot$ Q52 $\cdot$ Q55

\footnotetext{
I thank Michael A. Tamor and two anonymous referees for very useful comments and suggestions on a previous version of the paper. Part of this project was carried out while I was visiting the Department of Economics at the Universidad Autónoma de Madrid, the hospitality of which I gratefully acknowledge. I also acknowledge the nancial support from the Spanish Ministry of Science, Innovation and Universities through grant ECO-2016-76818-C3-2-P, and Research Project FEDERJA-145.
}

Anelí Bongers

abongers@uma.es

1 Department of Economics, University of Málaga, 29013 Málaga, Spain 


\section{Introduction}

The energy mix used in the economy is arguably one of the key factors in explaining the dynamic relationship among output, energy consumption, carbon emissions, and the environment (Golosov et al. 2014). However, existing environmental-economic models have focused on a variety of environmental policies, including Pigouvian taxes, abatement instruments, promotion of energy efficiency, limits to emissions, etc., with little attention to the implications of the energy mix and energy transition in linking economic activities with damages to the environment. Production activities requires the use of energy as an additional input to physical capital and labor. Pollutant emissions are not a direct by-product of production activities which would imply constant energy intensity, but they depend on the particular energy mix of the economy, where each type of energy source has a different impact on the environment. Emissions from alternatives energy sources are very heterogenous and therefore attention must be paid to the composition of the primary energy consumption. In general, we can distinguish between two types of energy sources: Renewable and non-renewable. Renewable energy source (hydroelectric power, geothermal, solar, wind and biomass), are considered "lean" energies sources, producing no direct greenhouse gases emissions. On the other side, non-renewable or fossil fuels (oil, natural gas, and coal), are "dirty" energies as they produce direct gas emissions although at different rates (coal produces more emissions than oil and natural gas). ${ }^{1}$

This paper contributes to the literature by studying how technological shocks affect the relationship between the environment and the energy mix, using an Environmental Dynamic Stochastic General Equilibrium (E-DSGE) model, and how "second-best" policies can, partially, internalize the negative externality created by emissions. The dynamic relationship between economic growth and environmental protection remains central for sustainable development, where environmental problems are generated by the economic activity can be an impediment for future economic growth (World Bank 2012). Figure 1 plots the energy intensity for the U.S. for the period 1950-2018, measured as the primary energy consumption (thousand BTU: British Thermal Unit) to GDP ratio. During the full period energy intensity declined from 15.12 to 5.45 , that is, a reduction of $63.96 \%$. During the same period, carbon emissions to GDP ratio (measured in metric tons carbon dioxide per million dollars) drops from 1040 to 284 units, a reduction of $72.69 \%$. Hence, not all decline in carbon emissions is explained by energy intensity decline. Reduction in energy intensity can be explained by sectorial change toward less energy intensity industries, and by energy efficiency technologies. Reduction in carbon emissions not accounted by energy intensity decline (about $12 \%$ for the U.S.) is explained by emissions technological change and by changes in the energy mix toward cleaner energy resources.

\footnotetext{
1 Nuclear energy power is not considered. This energy source does not produce gas emissions to the atmosphere but it produces other residuals that can damage the environment. As our focus here is on carbon emissions, we exclude nuclear energy (representing a $8.8 \%$ of total primary energy consumption in the U.S. in 2018), from our analysis.
} 


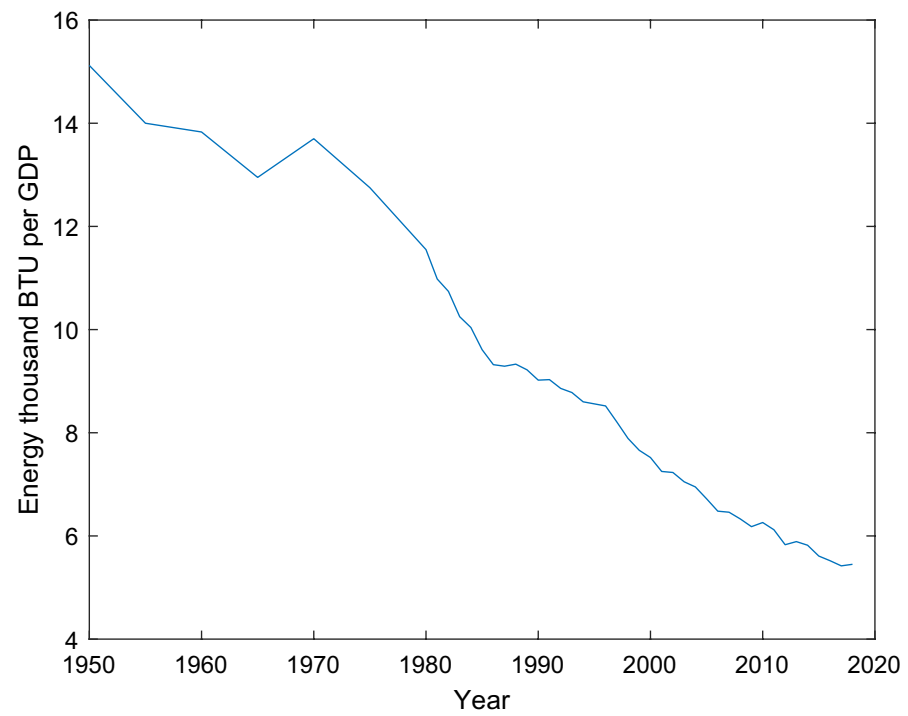

Fig. 1 Energy intensity in the US. Source: U.S. Energy Information Administration (EIA)

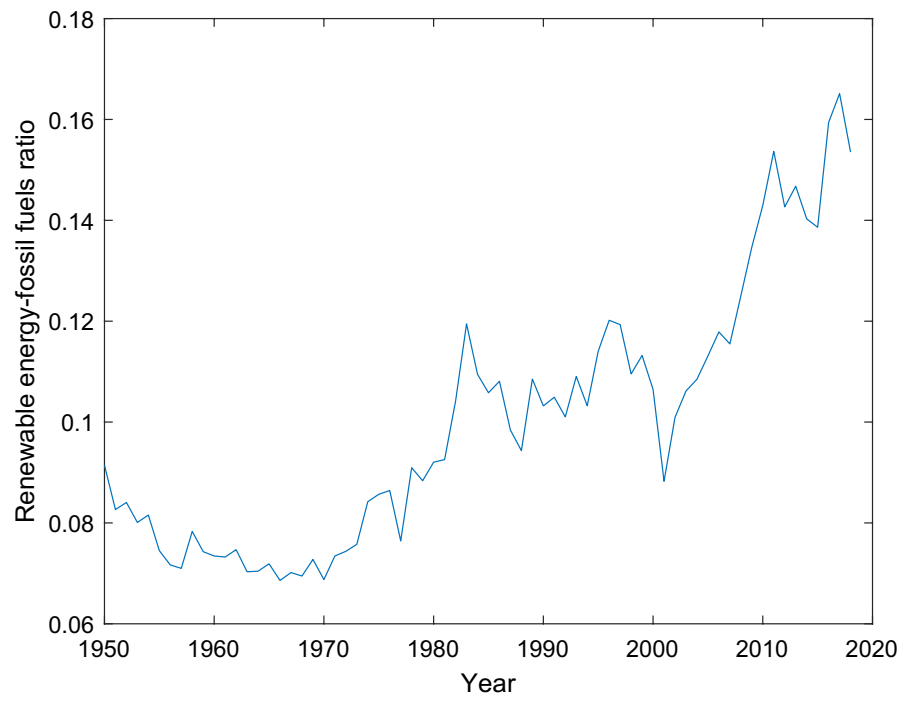

Fig. 2 Renewable to fossil fuels energy ratio. Source: EIA

Figure 2 plots the proportion of clean (renewable) energy with respect to fossil fuel energy consumption for the U.S. Whereas renewable energy represents a small fraction of total energy consumption, the impact on emissions is large, measured in term of forgone pollutant emissions by the replaced fossil fuels in the total energy consumption. Prior to 1970 , the ratio of renewable to fossil fuel energy declined, 
not as a consequence of a decrease in the use of renewable energy but to a higher expansion in fossil fuels consumption. During the decade of 1970s, it is observed a positive trend in the ratio, with a rapid expansion in renewable energy consumption, with a stagnation during the 1980s and even a decline in renewable energy ratio in the first years of the XXI Century. However, in the last years, renewable energy has been gaining positions with respect to fossil fuels.

The analysis done in this paper highlights the importance of the energy mix and energy policies implemented on the alternative energy sources in explaining environmental damage and the relationship between output and the environment. Whereas environmental policies considering a number of instruments have been widely studied in the literature, little focus has been placed in the implications of such policies on the energy mix and their impact on pollution. As pointed out by Atalla et al. (2017) energy mix is the result of the interaction of fuel prices, technology, and energy policies. First, the energy mix can be a policy driving decision by strategic reasons, mainly in economies without fossil fuels resources and as a way to diversify energy sources. Second, energy mix is also determined by environmental concerns. This is evident in the case of nuclear and coal electric power. Finally, the energy mix depends on the relative prices of the alternative energy sources which are mainly driven by technological factors. Tahvonen and Salo (2001) studied the transitions between non-renewable and renewable energy depending on the development stage of an economy. They obtain an inverted-U relationship between fossil fuel and the income level. Atalla et al. (2017) studied the role of fossil fuel prices relative to energy policy in driving the primary fossil fuel mix, and found that relative fossil fuel prices are the main source explaining the fossil energy mix in the U.S., Germany and the UK. However, the question remains open when not only fossil fuels are considered and also other primary non-fossil energy is taken into account. We depart from Atalla et al. (2017) study, by considering also the role of non-fossil fuel energy sources, and focusing on the consequences of technological shocks and fuel price shocks in explaining the energy mix and the impact on the environment.

This paper contributes to the literature by studying the relationship between production and social welfare, and the environment in a Dynamic Stochastic General Equilibrium (DSGE) model with alternative energy sources and endogenous energy transition, and studies how a second-best policy outcome by solving an optimal Ramsey problem differs from that of a central planner. In particular, we propose an economy where two alternative energy sources can be used in the production sector: one energy that produce emissions (i.e., fossil fuels), and another clean energy (i.e., renewable energy). In this framework emissions do not depend on final output, as it has been considered previously in the literature (see Fischer and Springborn 2011; Angelopoulos et al. 2010, 2013; Heutel 2012; Annicchiarico and Di Dio 2015), but on the consumption of fossil fuel energy. Our model considers a three inputs production function: physical capital, labor, and energy. Energy used in the production function is a composite of fossil fuels and renewable energy, and emissions depend on the quantity of fossil fuels used in the final energy mix. The stock of pollutants is an externality affecting negatively to final output (see Nordhaus 2008; Heutel 2012). Two types of technologies related to energy and emissions are considered: 
a technology that improves energy use efficiency, and a technology that reduces the quantity of emissions as a function of the quantity of fossil fuels.

We use the model to study the implications for the economy, the energy mix, and the environment of three shocks: an aggregate productivity shock, an energy use efficiency technological shock, and a clean energy technological shock. ${ }^{2}$ First, a positive neutral technological shock produces two opposite effects on output. The increase in aggregate productivity also increases output, as expected, but also increases the demand of the two types of energy, resulting in an increase of carbon emissions and in the accumulation of $\mathrm{CO}_{2}$ in the atmosphere. The higher level of $\mathrm{CO}_{2}$ concentration in the atmosphere has a negative impact on productivity, limiting the positive effects of the productivity shock on final output. We find that energy consumption is procyclical, as expected, but that the productivity shock reduces energy intensity and emissions per unit of output, consistent with empirical evidence. This is because the expansion in economic activity following the productivity shock increases the demand of both fossil fuels and renewable energy. As also the demand for renewable energy increases, emissions per energy unit decrease. However, it is also true that as a consequence of this productivity shock the renewable to fossil fuel energy ratio falls. The main results is that carbon emissions are procyclical but carbon emissions per unit of output is countercyclical.

Second, we study the implications of an energy efficiency technological shock common to the two energy sources. Energy efficiency technology provokes an increase in the quantity of energy used in the production process, increasing the level of emissions, which implies that the positive initial effect of a technological improvement in energy efficiency leads to an increase in energy consumption and in $\mathrm{CO}_{2}$ concentration in the atmosphere. Energy efficiency technology not only provokes the well-known "rebound effect" (Frondel et al. 2012; Gillingham et al. 2016), which implies that the positive initial effect of a technological improvement in energy efficiency leads to save less energy than initially expected, but we find that energy efficiency improvement increases energy consumption (a "rebound effect" above 100\%), the so-called "backfire effect" (Sorrell 2009; Gillingham et al. 2016), not as a consequence of the optimal response of households who does not internalize the cost of pollution, but as the optimal decision by a central planner to maximize social welfare. Importantly, the energy efficiency shock leads to a decline in the renewable-fossil fuels ratio, resulting in a technology that hinders the adoption of cleaner energy sources.

Third, we consider the case of a technological improvement in emissions (i.e., cleaner technologies as particulate filters and catalytic converters). This is an example of an asymmetric specific technological shock affecting only one of the energy sources: the "dirty" energy, as we assume that renewable energy does not produce carbon emissions. As one would expect, this technological improvement reduces emissions per fossil fuel unit, and hence, also emissions per output reduces. However, surprisingly, this technological change provokes an increase in the quantity of

\footnotetext{
${ }^{2}$ The effects of energy price shocks have been widely studied in the literature. See, for instance, Balke and Brown (2018); and Punzi (2019).
} 
"dirty" energy used in production and reduces the use of renewable energy. Therefore, technological change associated to emissions promotes the use of "dirty" energy sources as the negative externality produced by this energy declines. These results show that environmental policies promoting investment in energy efficiency and emissions efficiency technologies have different effects on the stock of $\mathrm{CO}_{2}$ concentration in the atmosphere; whereas the former increases the stock of $\mathrm{CO}_{2}$, the latter reduces the stock of $\mathrm{CO}_{2}$. Nevertheless, both policies are an obstacle to energy transition from non-renewable to renewable energy sources.

Finally, we consider the case of a decentralized economy where the government uses an optimal specific tax on fossil fuel. We assume a benevolent government that solves a Ramsey problem by choosing a per unit tax on fossil fuel consumption to maximize total expected discounted utility, subject to the first-order conditions for household's utility and firms' profits maximization. We calculate the steady state of the economy for three cases: Centralized economy, laissez faire, and the Ramsey problem. We found that distortions introduced by pollution implies a reduction in consumption and an energy mix biased to the use of fossil fuels compared to the central planner solution, where more renewable (clean) energy is used. A benevolent government choosing the optimal tax on fossil fuels shift away the economy from the laissez-faire equilibrium to a Ramsey equilibrium which is close to the social planner solution. The optimal tax policy changes the energy mix of the economy, reducing emissions and increasing output and welfare. Whereas differences in output are small in all three scenarios, the energy mix, emissions and social welfare show important differences across them. The most important result is that the second best policy resulted from the Ramsey problem is able to shift the competitive equilibrium with no internalization of the environmental externality to an equilibrium close to the first best where welfare losses are small compared to the laissez faire scenario.

The rest of the paper is structured as follows. Section 2 presents an E-DSGE model including non-renewable and renewable energy sources as an additional input factor to capital and labor, and solves the model for a centralized economy where the environmental externality is internalized. Section 3 presents the calibration of the parameter of the model. Section 4 studies the dynamic properties of the model to different technological shocks. Section 5 solves the model for a decentralized economy where a benevolent government chooses an optimal specific tax on fossil fuels to maximize social welfare. Finally, Section 6 presents some conclusions.

\section{An E-DSGE model with energy mix}

In this section, we develop an E-DSGE model with a three-inputs production function: physical capital, labor and energy. We consider two types of energy sources: Fossil fuels and renewable energy. We assume that for production some energy source must be used as an additional input to capital and labor, and that burning fossil fuels releases greenhouse gases $\left(\mathrm{CO}_{2}\right)$ into the atmosphere. Renewable energy is a clean energy as it does not produce emissions. The stock of pollution is a negative externality that will negatively affect aggregate productivity. The model includes three technological shocks: an aggregate productivity shock, an energy efficiency 
technological shock, and an emission efficiency technological shock. Additionally, the model considers an oil price shock.

\subsection{Household utility function}

The economy is populated by an infinitely lived representative agent who maximizes the expected value of her lifetime utility. Households obtain utility from consumption and leisure. Household utility function is defined as:

$$
U\left(C_{t}, L_{t}\right)=\frac{C_{t}^{1-\gamma}}{1-\gamma}-\omega \frac{L_{t}^{1+\frac{1}{v}}}{1+\frac{1}{v}}
$$

where $C_{t}$ is the consumption, $L_{t}$ and is working hours, $\gamma$ is the constant relative risk aversion parameter, $v$ is the Frisch elasticity of labor supply, and $\omega>0$ represents the willingness to work. We consider a centralized economy where a central planner maximizes social welfare. The resource constraint for this centralized economy is defined as:

$$
C_{t}+I_{t}+O_{t}+S_{t}=Y_{t}
$$

where $I_{t}$ is investment in physical capital, $Y_{t}$ is final output (total income), $O_{t}$ is the quantity of fossil fuel, and $S_{t}$ is the quantity of renewable energy. For simplicity it is assumed that the quantity of renewable energy is exogenously given and that no restriction on the extraction of non-renewable energy exists.

In the literature, we find two alternative ways to introduce the negative externality produced by damages to the environment. The first is the introduction of this externality in the aggregate production function. This is the case, for instance, in Heutel (2012) and Golosov et al. (2014). It is assumed that climate change damages the environment and hence production, by reducing productivity. Pollution, defined as the $\mathrm{CO}_{2}$ concentration in the atmosphere, is considered as a stock variable that accumulate with carbon emissions. Therefore, atmospheric carbon concentration has a negative economic impact reducing final output. The second way to consider externalities from pollution is by assuming that it is can be either a flow or a stock variable, negatively affecting households' utility function. Examples of this modeling are John and Pecchenino (1994), Jones and Manuelli (1995), and Stokey (1988). As pointed out by John and Pecchenino (1994), in general, environmental externalities could arise from production or consumption and could affect welfare or productivity. Following Nordhaus (2007) and Heutel (2012), our model only consider a pollution externality in the production.

Investment accumulates into physical capital. Physical capital stock accumulation equation is defined as:

$$
K_{t+1}=\left(1-\delta_{k}\right) K_{t}+I_{t}
$$

where $K_{t}$ is the capital stock and $\delta_{k}\left(0<\delta_{k}<1\right)$ is the depreciation rate of physical capital. 


\subsection{Emissions and the stock of pollution}

In the environmental-economic literature, a number of works assumes that emissions are a function of final output. However, this assumption neglects the possibility of declines in emissions when output increases. In this context, a negative relationship between emissions and output can only be obtained under technological change affecting abatement and/or emissions. A more realistic assumption is that carbon emissions depends on the energy mix combining both non-renewable dirty energy with renewable clean energy sources. To consider that possibility, in our model, carbon emissions are related with the energy source used in the final production. That is, carbon emission is assumed to be generated by the use of fossil fuels, whereas we assume that renewable energy sources do not produce emissions. In particular, we assume that damages are proportional to the quantity of fossil energy.

$$
X_{t}=\eta B_{t} O_{t}
$$

where $\eta>0$ represents the carbon content of fossil fuel or carbon emission per fossil fuel unit, and $B_{t}$ is an exogenous technology for emission (emissions efficiency), representing fossil fuels consumption technologies that reduce gas emissions. Hence, we are assuming that the change in emissions is equal to the change in fossil fuel consumption. Hence a technological improvement that reduces emissions by fossil fuels energy unit is represented by a decrease in that exogenous shock (i.e., catalytic converter technology). We abstract from the fact that the level of emissions of the fossil fuel mix are different depending on the share of oil, coal, and natural gas, where emissions produced by natural gas are lower than emissions from coal. For instance, if the share of gas increases at the expense of coal, this results in a "cleaner" energy mix. Emissions efficiency technology is assumed to be exogenous and follows a first-order autorregresive process:

$$
\log B_{t}=\left(1-\rho_{B}\right) \log \bar{B}+\rho_{B} \log B_{t-1}+\varepsilon_{t}^{B}
$$

where $\bar{B}$ is the steady state value for the emission technology, $\rho_{B}<1$, and $\varepsilon_{t}^{B}$ is a i.i.d. innovation in the stochastic process. Emission efficiency technological progress is represented by a negative shock to $B_{t}$.

Emissions accumulate into a stock of pollutants, $Z_{t}$, where the atmospheric carbon accumulation process is given by,

$$
Z_{t+1}=\left(1-\delta_{z}\right) Z_{t}+X_{t}
$$

where $\delta_{z}\left(0<\delta_{z}<1\right)$ is the stock of pollutants natural decay rate. ${ }^{3}$

\footnotetext{
${ }^{3}$ We do not study the role of technological progress in Carbon Dioxide Removal (CDR). CDR comprises a set of chemical and biological instruments that can reduce the amount of $\mathrm{CO} 2$ already in the atmosphere. $\mathrm{CDR}$ technologies includes capture and storage of $\mathrm{CO}$, biochar (a pyrolysis of biomass process), ocean fertilization, and enhanced weathering. These technologies change the accumulation process of the stock of pollution but without affecting emissions.
} 


\subsection{Production technology}

The model considers a three-factor aggregate production function: physical capital, labor, and energy. We assume the following aggregate production function, that exhibits constant returns to scale on all factors, represented by a Cobb-Douglas production function:

$$
Y_{t}=A_{t} \exp \left(-\phi Z_{t}\right) K_{t}^{\alpha_{1}}\left(D_{t} E_{t}\right)^{\alpha_{2}} L_{t}^{1-\alpha_{1}-\alpha_{2}}
$$

where the term $\exp \left(-\phi Z_{t}\right)$ represents the cost of the damage of pollutants measured as forgone output, and $\phi>0$ is a parameter governing the elasticity of aggregate productivity with respect to the stock of pollutants. ${ }^{4}$ Final output is influenced by a neutral technology component $A_{t}$ (total factor productivity, TFP) and by an externality due to emissions. This externality may be included in the economy by affecting the utility function, instead of the production function. However, the literature considers that this alternative is more appropriate for pollutants that affect health directly and that the stock of pollution is expected to affect the production possibilities of the world economy (Nordhaus 2008).

Energy is a Armington aggregator of fossil fuel and renewable energy:

$$
E_{t}=\left[\mu O_{t}^{\frac{\sigma-1}{\sigma}}+(1-\mu) S_{t}^{\frac{\sigma-1}{\sigma}}\right]^{\frac{\sigma}{\sigma-1}}
$$

where $\sigma>1$ is the elasticity of substitution between both types of energies and $\mu$ is a parameter representing the weight of each type of energy in the final energy mix. The model assumes that both types of energies are imperfect substitutes. The amount of energy used, $E_{t}$, is influenced by an energy-augmenting technological change of the economy, denoted by $D_{t}$. The higher is $D_{t}$, the more energy efficient is the production sector. Total Factor Productivity is assumed to be exogenous and follows a first-order autorregresive process:

$$
\log A_{t}=\left(1-\rho_{A}\right) \log \bar{A}+\rho_{A} \log A_{t-1}+\varepsilon_{t}^{A}
$$

where $\bar{A}$ is the steady state value for TFP, $\rho_{A}<1$, and $\varepsilon_{t}^{A}$ is a i.i.d. innovation in the stochastic process. A similar stochastic process is assumed for $D_{t}$ :

$$
\log D_{t}=\left(1-\rho_{D}\right) \log \bar{D}+\rho_{D} \log D_{t-1}+\varepsilon_{t}^{D}
$$

\subsection{Centralized equilibrium}

Given the existence of a negative externality on the environment, we consider a centralized economy. The central planner solution is derived by choosing the path for

\footnotetext{
${ }^{4}$ Alternatively, the negative effect of $\mathrm{CO}_{2}$ concentration in the atmosphere on productivity can be modeled as a function of the temperature. See Nordhaus (2007).
} 
consumption, labor, capital, fossil fuels, renewable energy, and stock of pollution, to maximize the sum of the discounted utility subject to resource, technology, and carbon emissions constraints. From the first order conditions for the centralized problem, we obtain the following equilibrium conditions: ${ }^{5}$

$$
\begin{gathered}
L_{t}^{\frac{1}{v}+1}=\frac{\left(1-\alpha_{1}-\alpha_{2}\right) Y_{t}}{\omega C_{t}^{\gamma}} \\
\frac{C_{t+1}^{\gamma}}{C_{t}^{\gamma}}=\beta\left[\left(1-\delta_{k}\right)+\alpha_{1} \frac{Y_{t+1}}{K_{t+1}}\right] \\
1=\alpha_{2}(1-\mu) \frac{Y_{t} S_{t}^{\frac{-1}{\sigma}}}{\mu O_{t}^{\frac{\sigma-1}{\sigma}}+(1-\mu) S_{t}^{\frac{\sigma-1}{\sigma}}} \\
Y_{t+1}=\frac{\left[\begin{array}{l}
\left.\alpha_{2} \mu \frac{Y_{t+1} O_{t+1}^{\frac{-1}{\sigma}}}{\mu O_{t+1}^{\frac{\sigma-1}{\sigma}}+(1-\mu) S_{t+1}^{\frac{\sigma-1}{\sigma}}}\right]\left(1-\delta_{z}\right) \\
\phi \eta B_{t+1}
\end{array}\right.}{-\frac{C_{t}^{-\gamma}\left[1-\alpha_{2} \mu \frac{Y_{t} O_{t}^{\frac{-1}{\sigma}}}{\mu O_{t}^{\frac{\sigma-1}{\sigma}}+(1-\mu) S_{t}^{\frac{\sigma-1}{\sigma}}}\right]}{\beta C_{t+1}^{-\gamma} \phi \eta B_{t}}}
\end{gathered}
$$

where $\beta$ is the discount factor. Expression (11) is the optimal labor supply. Expression (12) is the optimal consumption path. Expression (13) is the equilibrium condition for renewable energy consumption, whereas expression (14) indicates the optimal stock of pollution. Notice that the price for the fossil fuels includes the pollution externality cost.

\section{Data and calibration}

This section presents the calibration of the parameters of the model. Since the model is composed by macroeconomic parameters and also parameters related to emissions, we use different sources for its calibration. Macroeconomic parameters are calibrated from the Real Business Cycle literature, while energy and emissions parameters are taken from studies related to environment and climate change, mostly from Stern (2012), Heutel (2012). We use data for the U.S. The discount factor (for annual data) is fixed to 0.975 , whereas the relative risk aversion parameter is equal

\footnotetext{
5 See Bjørnland and Larsen (2016) and Evgenidis et al. (2020) for examples of analysis with a decentralized economy.
} 
to 1.2, values that are standard in the literature. Parameter values for labor supply are selected just to replicate the observed fraction of time devoted to working activities of 0.33 , as reported by the BLS (Bureau of Labor Statistics). Production function technological parameters are taken from the EIA (U.S. Energy Information Administration) and the BEA (Bureau of Economic Analysis). We assume that the fraction of labor compensation over total income is 0.65 . As the production function assumes the existence of constant returns to scale, the sum of the technological parameters for the other two inputs, capital and energy, must be 0.35 . The technological parameter governing the elasticity of output with respect to energy is obtained from the proportion of energy consumption over GDP and is estimated to be 0.0982 . Therefore, the elasticity of output with respect to physical capital is 0.2518 .

The parameter representing the proportion of fossil fuels on total energy mix is fixed at 0.84 , accounting the rest 0.16 for renewable energy. The parameter governing the elasticity of substitution between fossil fuels energy and renewable energy is fixed at 1.5. Finally, environmental parameters are taken from Nordhaus (2008) and calibrated simultaneously to produce a loss of productivity of $1 \%$ in the steady state. The pollution decay rate is fixed at 0.012 , as it is standard in the literature, which corresponds to a half-life of carbon concentration of around 58 years. Heutel (2012) estimates a elasticity of emissions with respect of output of 0.696 , whereas the productivity loss from pollution is estimated to be of $0.26 \%$. We fix the emission parameter to be 0.1 , resulting in a pollution damage parameter of 0.0875 to reduces productivity a $1 \%$ in steady state. Parameters for the autoregressive exogenous TFP shock as estimated as the Solow's residual from the production function. Estimated values are a persistence parameter of 0.923 and a standard deviation of 0.0079 . Finally, given the uncertainty about parameters for the exogenous processes for energy efficiency and emissions efficiency shocks, we use an autorregresive parameter of 0.9 , and a standard deviation to 0.01 for both shocks, as these values

Table 1 Calibration of the parameters

\begin{tabular}{llll}
\hline & Parameter & Definition & Value \\
\hline Preferences & $\beta$ & Discount factor & 0.97 \\
& $\gamma$ & Risk aversion & 1.2 \\
& $\omega$ & Labor weight & 15.60 \\
& $v$ & Frisch elasticity parameter & 0.72 \\
Technology & $\alpha_{1}$ & Output-capital elasticity & 0.2518 \\
& $\alpha_{2}$ & Output-energy elasticity & 0.0982 \\
Energy & $\delta_{k}$ & Physical capital depreciation rate & 0.06 \\
& $\mu$ & Weight of fossil fuels & 0.83 \\
Environment & $\eta$ & Energy sources substitution & 1.50 \\
& $\delta_{z}$ & Emissions parameter & 0.1 \\
& $\phi$ & Pollutant stock decay rate & 0.012 \\
& & Pollution damage parameter & 0.0875 \\
\hline
\end{tabular}

Note: Calibration of preference parameters are standard in the literature. For technology, energy, and environmental parameters we use some targets using data from EIA 
are frequently used in the literature for a variety of shocks (see, for instance, Smets and Wouters (2007)). A summary of the calibration of the parameters is presented in Table 1.

\section{Technological shocks}

The calibrated model is used to study how the economy, the energy mix, the level of emissions, and the environment, respond to different shocks. In particular, we are interested in studying the impact of different technological shocks on the energy mix and emissions, and their implications on the shift from fossil fuels to renewable energy sources that can increases output without further damages to the environment. We simulate three technological shocks: a total factor productivity shock (i.e., a neutral technological shock), an energy efficiency technological shock (energyaugmented shock), and an emissions efficiency technological shock.

\subsection{Aggregate productivity shock}

First, we present some simulations to show the dynamics of the model economy via impulse-response functions to an aggregate productivity shock. This first exercise considers the case of an exogenous idiosyncratic positive neutral shock to the economy, represented by an increase in total factor productivity (TFP), $A_{t}$. Expansion of economic activity following the productivity shock is expected to increase energy consumption, but its effects on $\mathrm{CO}_{2}$ emissions will depend on how the energy mix will change. Empirical evidence shows that total energy consumption is procyclical, a result which is also consistent with the model. The key question here is, given the existence of two alternative energy sources with a separate effect on emissions, how the shock affects the energy mix and damages to the environment.

Figure 3 plots the impulse-response for the main aggregate variables of the economy, as percentage deviations from the steady state. As expected, the rise in total factor productivity increases output. This rise in output is distributed between consumption and investment, similar to the response observed in a standard DSGE model. The amount of inputs also increases, including energy, given that marginal productivity of each input is now higher, as this is the case of a neutral technological shock. The demand of both types of energy increases, being higher the response of fossil fuels to the shock compared to that of renewable energy. As a consequence of the increase in fossil fuels consumption, the level of emissions also increases. Therefore, our model produces, using our benchmark calibration, a positive relationship between output and environmental deterioration when an aggregate productivity shock occurs. Emissions are procyclical as the neutral technological shock increases the demand for all energy sources. Importantly, the effects of the positive aggregate productivity shock on economic activity are mitigated due to the counter-effect of the pollution externality by reducing productivity gains following the shock. The higher the cost of the pollution externality, the less the output increases following a positive 

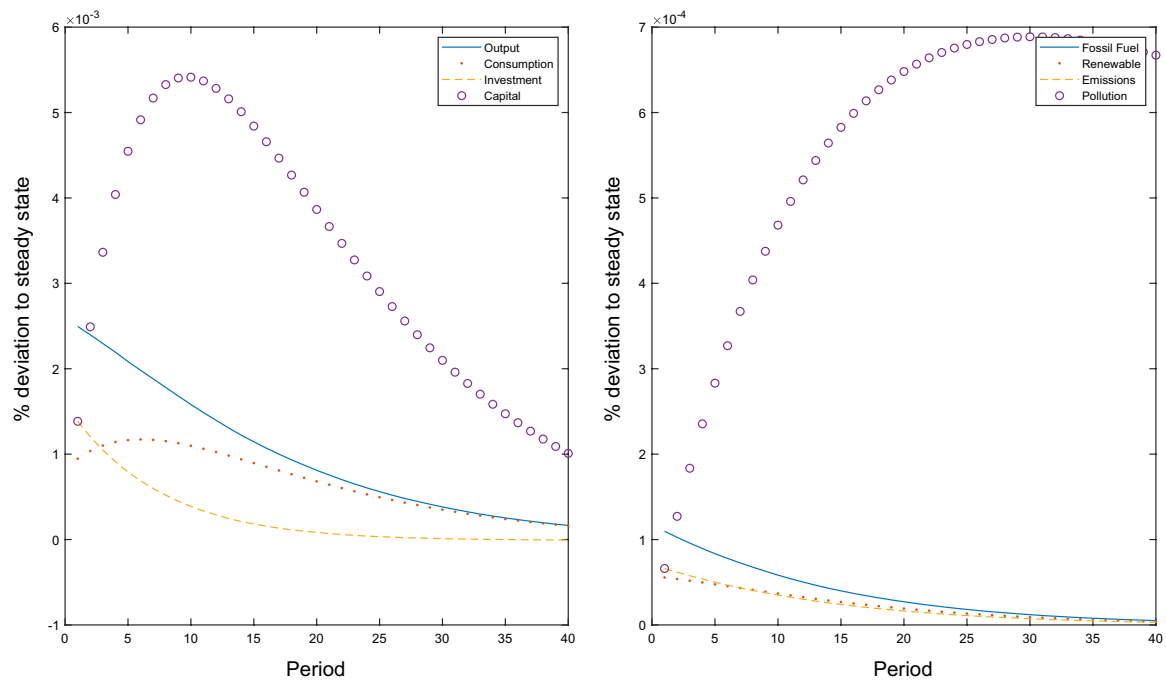

Fig. 3 Impulse-response functions to a positive Total Factor Productivity shock (one standard deviation). Percentage deviation of each variable with respect to its steady state.

TFP shock. These results are consistent with the findings of Heutel (2012), as he found that carbon emissions are significantly procyclical with an elasticity with respect to GDP between 0.5 and 0.9 . However, that result emerges directly from the modelling assumption that emissions is a proportion of output. In the model presented in this paper, emissions are not proportional to output but to the consumption of fossil fuel, but we also find that carbon emissions are procyclical, as the neutral technological shock increases the demand of both renewable and fossil fuels energy sources. Our estimated value is an elasticity of 0.8142 , a value in the range estimated by Heutel (2012).

This simulation exercise illustrates that a substitution effect of "dirty" by "clean" energy does not happen endogenously for the benchmark calibration, and hence, expansion of the economic activity does not produces endogenous energy transition from fossil fuels to renewable energy sources. Only when the cost in foregone output is higher enough, would changes in the energy mix reduces the use of fossil fuels to mitigate environmental damage. But this is not the case in our simulated economy, where the profits from increasing fossil fuels consumption are higher than the cost of damages to the environment. The other important result we obtain is that the productivity shock reduces energy intensity. In response to the shock both output and energy consumption increase, but where the increase in the first is higher than in the second. Therefore, we show that TFP shocks are an important source in explaining the decline in energy intensity observed in the data. However, from the benchmark simulation it is clear that energy intensity decline does not necessarily implies a lower level of emissions when output growths. Finally, another outstanding result is that the productivity shock reduces the level of carbon emissions per unit of output as a consequence of an expansion in renewable energy sources. Nevertheless, total 
Table 2 Cyclical properties of U.S. and model-generated data*

\begin{tabular}{lll}
\hline & Data & The model \\
\hline$\sigma_{c} / \sigma_{y}$ & 0.5876 & 0.7921 \\
$\sigma_{i} / \sigma_{y}$ & 2.7423 & 2.1775 \\
$\sigma_{o} / \sigma_{y}$ & 1.7239 & 1.6439 \\
$\sigma_{s} / \sigma_{y}$ & 3.6665 & 1.0936 \\
$\sigma_{x} / \sigma_{y}$ & 1.6578 & 1.7379 \\
$\operatorname{corr}(y, c)$ & 0.8397 & 0.9594 \\
$\operatorname{cor}(y, i)$ & 0.9218 & 0.9108 \\
$\operatorname{corr}(y, o)$ & 0.5972 & 0.9957 \\
$\operatorname{corr}(y, s)$ & 0.2343 & 0.9997 \\
$\operatorname{corr}(y, x)$ & 0.5968 & 0.9953 \\
$\operatorname{corr}(o, x)$ & 0.9831 & 1.0000 \\
\hline
\end{tabular}

* U.S. data (HP filtered) for the period 1980:I-2019:IV.

The standard deviations and correlations are sample means of artificial data for 1000 simulations, each simulation with 180 periods, the number of quarters in the U.S. data

carbon emissions increases as a consequence of the higher fossil fuels consumption, and hence, the accumulation of $\mathrm{CO}_{2}$ in the atmosphere accelerates.

Table 2 compares observed moments for output, consumption, investment, fossil fuel, renewable energy and emissions, and simulated figures from the model following a TFP shock. Relative standard deviation of fossil fuel to output is 1.72 in the data, compared to a value of 1.63 produced by the model. Additionally, the model is able to matches the relative standard deviation of emissions to output with that observed in the data. Therefore, the model explains quite well observed variability for these key variables. However, little predicting power of the model for the relative standard deviation of renewables and correlations is obtained. Relative standard deviation of renewable to output is around 3.67 in the data, indicating that volatility in the production of renewable energy is much larger compared to that of aoutput. However, the model generates a relative standard deviation much lower, of only 1.09 , where simulated volality of renewables is similar to that of output. On the other hand, the model produces a correlation of energy sources, and emissions with output close to one. However, the data show a much lower correlation with output of theses variables; around 0.6 for fossil fuels and emissions, and 0.23 for renewables, indicating that other shocks, appart from technological shocks, drive the relationship between output, energy and emission across the business cycle. Finally, the model produces a correlation between fossil fuel and emissions of one by construction. However, this value is very close to the one observed in the data of 0.98 .

\subsection{Energy efficiency shock}

Second, we study the response of the economy to a shock that increases energy efficiency, $D_{t}$. Given that most anthropogenic emissions of greenhouse gases released into the atmosphere are generated by energy consumption, environmental policies 

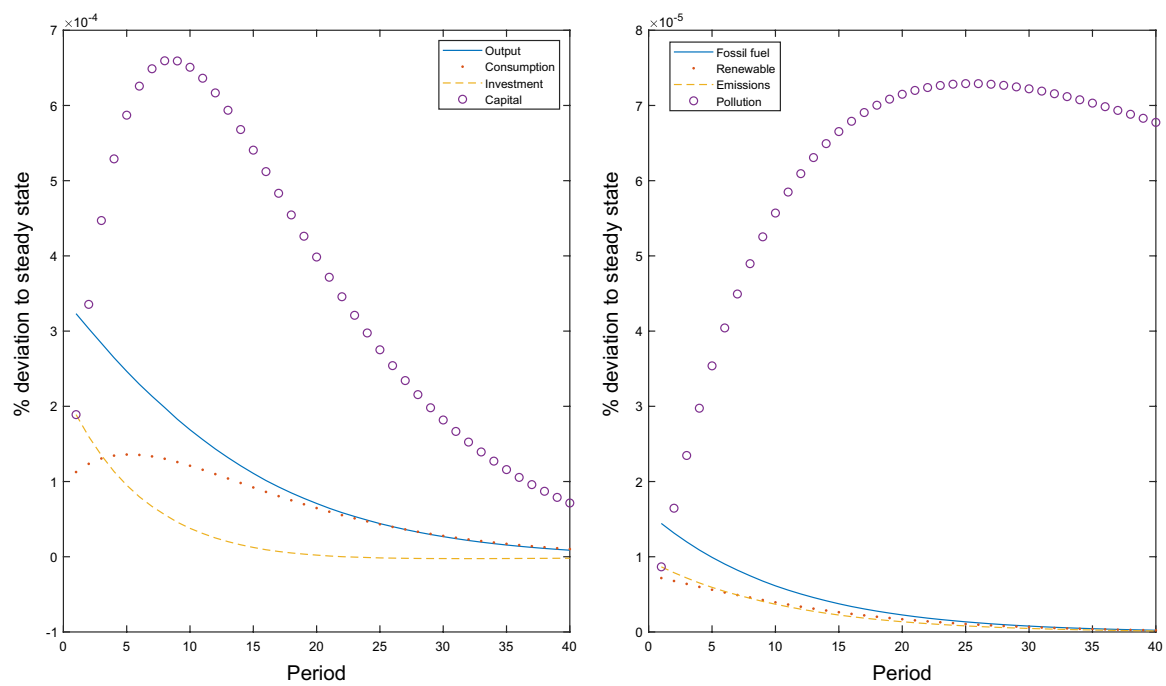

Fig. 4 Impulse-response functions to an energy efficiency technological shock (one standard deviation). Percentage deviation of each variable with respect to its steady state

have focused on promoting energy efficiency as an instrument to reduce emissions. Energy efficiency refers to technological changes that reduce the amount of energy needed to produce a given quantity of goods and services in combination with the other inputs, resulting in a decline in energy intensity (an energy-augmenting technical change). This shock is general to the consumption of energy per output unit, and hence, affects symmetrically to the two energy sources. The implications of energysaving technological changes on the economy have been widely studied in the literature, for instance, in Newell et al. (1999). They obtain the energy price changes are the main driving force for energy-efficiency technological change. Here, we pay attention to how energy efficiency changes the energy mix. We find that energy efficiency technology not only provokes the well-known "rebound effect" (Frondel et al. 2012; Gillingham et al. 2016), which implies that the positive initial effect of a technological improvement in energy efficiency leads to save less energy than initially expected, but we find that energy efficiency improvement increases energy consumption, resulting in the so-called "backfire effect" (Sorrell 2009; Gillingham et al. 2016), not as a consequence of the optimal response of households who does not internalize the cost of pollution, but as the optimal decision by a central planner to maximize social welfare. Energy intensity reduces as energy efficiency increases, but surprisingly also the level of emissions increases and hence, energy efficiency policies have harmful consequences for the environment as they incentive energy consumption.

Figure 4 plots the impulse-response functions of the main variables of the model to an energy-efficiency technological shock. As expected, the response of output is positive, as the energy-saving shock increases productivity of one of the inputs: energy. As a consequence, the response of consumption and investment is also 
positive, indicating that this efficiency technology shock increases physical capital accumulation. What is more important is that it is observed that gains in energy efficiency lead to an increase in the demand of energy. As the shock is common to the two energy sources, both the demand of non-renewable and the demand renewable energy increase, where the increase in renewable energy is larger than the rise in fossil fuels energy. This larger response of the renewable energy is consequence of the increase in the relative price of fossil fuels energy, as the pollution externality cost rises the total cost of fossil fuels. However, the increase in the user cost of fossil fuels caused by the pollution externality cost is lower than the reduction in the user cost of this energy source due to the improvement in energy-efficiency, resulting in a final rise in the quantity of energy used in production, and resulting in more emissions.

These results are consistent with the so-called "rebound effect" or "take-back effect" described in the literature on energy-efficiency, consisting in a reduction in the expected gains or, even in a loss, from new technologies that increase the efficiency of energy use. That effect is derived from the optimal response of economic agents to a technological improvement in energy efficiency, leading to a rise in energy consumption. This is the mechanism that we observe in our model, where this technological shock provokes a rise in the quantity of energy used in the production activity, as the rise in energy-efficiency is equivalent to a reduction of the energy price. For the benchmark calibration of the model, we obtain a "rebound effect" higher than $100 \%$, the so-called backfire effect, which generates a negative effect on the environment, as the technological improvement in energy efficiency implies a rise in the emission of pollutants. Given that energy is a normal and, also an ordinary good, the rebound effect can be explained according to an income and a substitution effects. In our theoretical framework this technological shock increases productivity of energy in producing the final good, increasing the demand of this input and reducing the demand for the other inputs. This is the substitution effect. On the other hand, the rise in the productivity of one of the factors, increases aggregate productivity, increasing the demand for all factors. This is the income effect. Both effects contribute to the observed backfire effect and the consequent increase in the carbon concentration in the atmosphere.

\subsection{Emissions efficiency technology shock}

Finally, we study the implications of a technological change that increases emissions efficiency, i.e., a negative shock to $B_{t}$. This shock implies a reduction in the level of emissions per fossil fuel unit used in the production process. For instance, this is the case of an improvement in catalytic converter technology. This shock can also be interpreted as an improving in abatement technology. In this case, the technological change does not affect energy efficiency but emissions efficiency specific to fossil fuels consumption, resulting in an asymmetric shock depending on the type of energy source consumed. Therefore, this shock will reduce the level of emissions per fossil fuel unit, but it does not directly affect to the use of renewable energy sources, as the later is a "clean" energy, and thus, not related to emissions. However, given 

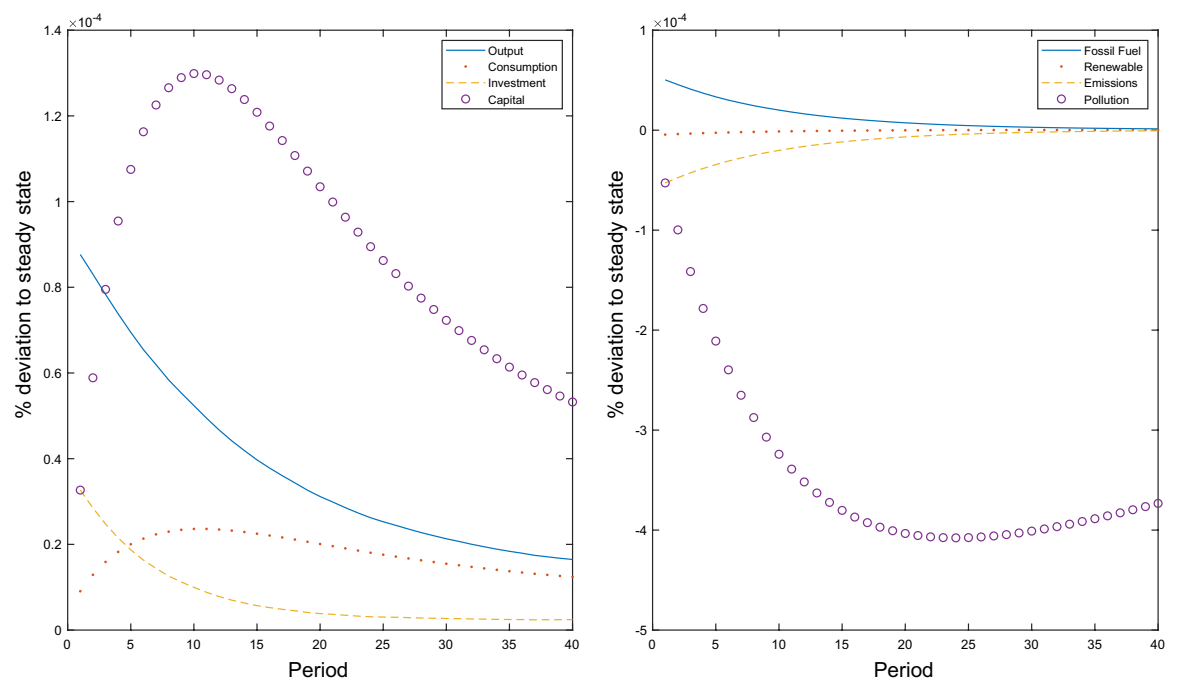

Fig. 5 Impulse-response functions to an emissions effiency technological shock (one standard deviation). Percentage deviation of each variable with respect to its steady state

the general equilibrium effects generated by our model economy, this specific shock to the use of non-renewable energy will also change renewable energy consumption.

As shown in Figure 5, output increases in response to this technological shock. This change in total output results in a rise in consumption and investment. Investment shows a positive response in the following periods, increasing the stock of physical capital. Importantly, the amount of energy used in production increases but, in balance, produces a lower level of emissions. The economic intuition behind these effects is the following. This shock is equivalent to a reduction the cost of the pollution externality, increasing productivity and reducing the user cost of fossil fuels energy. The positive effect on economic activity is explained by two forces. First, the shock reduces damages to the environment and relieving its harmful effects on productivity and expanding output. This initial expansion in output results in higher investment, increasing capital stock. Therefore, the effects of an emission efficiency shock on the economy are, qualitatively, similar to those of an aggregate productivity shock.

Investing in cleaner technologies has two opposite effects. First, the shock means that less carbon emissions are generated by unit of fossil fuel consumption. However, total carbon emissions will depends not only on the direct effect of the shock on emissions per fossil fuel unit but on the indirect effect of the shock on fossil fuels consumption. Indeed, it is observed an increase in energy consumption, at the same time that the level of emissions declines. Second, there is an increase in the use of fossil fuels and a reduction in the renewable energy use. These two different results are consequence of the different impact of this technological shock over the two energy sources. The shock directly affects to the use of the fossil fuels energy source. The shock reduces the level of emissions per unit of energy, reducing the externality cost of using the "dirty" energy. As an indirect effect, that changes the 
relative price of both energy sources, reducing the price of the fossil fuel energy relative to the price of the renewable energy source. This provokes a substitution of renewable energy by fossil fuels energy. The rise in the demand of fossil fuels is larger than the down of renewable energy, resulting in a total rise in the demand of energy.

In sum, an emission efficiency technological shock is equivalent to a reduction in the user cost of the "dirty" energy, and hence, increasing the relative price of the "clean" energy relative to the "dirty" energy. Indeed, the literature suggests that the relative low prices of fossil fuels had driven technological progress to fossil fuels intensive industries. Emission efficiency technological change provokes similar results, having a negative impact on energy transition to renewable energy sources. Overall, the social cost of energy declines following this shock, increasing the quantity of energy used in the production. Nevertheless, the effect of the rise in the quantity of energy used for production is compensated by the reduction in emissions by energy unit, resulting in an environmental quality improvement.

\section{Decentralized economy}

The model presented above assumed a centralized economy in which a benevolent central planner chooses optimal values for output, consumption, investment, labor, energy mix, and emissions simultaneously to maximize social welfare. In that context, the central planner chooses the optimal energy mix (proportions of fossil fuel and renewable energy) such as the negative externality produced by the use of fossil fuel is internalized. However, the solution of the model for a centralized economy does not consider any particular policy to internalize the negative externality, as it is assumed that the central planner can choose optimal quantities for all variables, including environmental ones. In this section, we solve the model for the case of a decentralized economy. Under "laissez faire", households maximize utility and firms maximize profits without taking into account the negative pollution externality provoked by the use of fossil fuels. This would lead to an excessive consumption of fossil fuels with respect to the optimal, increasing pollution and generating climate damages that lead to productivity losses. The competitive equilibrium is extended by including a government that can implement a specific environmental policy by solving a Ramsey problem. In this context, the government can implement an optimal policy by, given the optimizing behavior of both households and firms, introducing an additional distortion that can off-set the environmental negative externality. We consider that the government use a tax policy where the instrument is a specific tax (a per unit tax) on fossil fuel consumption. Heutel (2012) showed that the outcome under a Ramsey optimal fiscal policy can also be obtained by a government implementing a Ramsey optimal quantity policy.

First, we consider a decentralized economy populated by households and firms, in which each agent takes optimal decisions without internalizing the cost of the environmental externality. In this framework, it is assumed that household maximize discounted utility subject to the budget constraint by choosing optimal path for 
consumption, labor supply, and capital stock. Household maximization problem is defined as,

$$
\max _{\left\{C_{t}, L_{t}, K_{t}\right\}} \sum_{t=0}^{\infty} \beta^{t}\left(\frac{C_{t}^{1-\gamma}}{1-\gamma}-\omega \frac{L_{t}^{1+\frac{1}{v}}}{1+\frac{1}{v}}\right)
$$

where the budget constraint is given by:

$$
C_{t}+I_{t}=W_{t} L_{t}+R_{t} K_{t}
$$

where $W_{t}$ is wage, and $R_{t}$ is capital return. From the household's maximization problem we find the following two equilibrium conditions, representing optimal labor supply and the optimal consumption path, respectively,

$$
\begin{gathered}
\omega L_{t}^{\frac{1}{v}}=W_{t} C_{t}^{-\gamma} \\
\left(\frac{C_{t+1}}{C_{t}}\right)^{\gamma}=\beta\left[1-\delta_{k}+R_{t+1}\right]
\end{gathered}
$$

Next, consider the behavior of the representative firm. In a market economy, firms maximize profits and do not internalize the cost of emissions, that is, they take the stock of pollution as given. Profits are defined as:

$$
\Pi_{t}=Y_{t}-W_{t} L_{t}-R_{t} K_{t}-P_{o, t} O_{t}-P_{S, t} S_{t}
$$

where $P_{o, t}$ is the price of fossil fuel, and $P_{S, t}$ is the price of renewable energy.

First order conditions from profits maximization, determine the prices for inputs, and are given by,

$$
\begin{gathered}
W_{t}=\left(1-\alpha_{1}-\alpha_{2}\right) \frac{Y_{t}}{L_{t}} \\
R_{t}=\alpha_{1} \frac{Y_{t}}{K_{t}} \\
P_{s, t}=\alpha_{2}(1-\mu) \frac{Y_{t} S_{t}^{\frac{-1}{\sigma}}}{\mu O_{t}^{\frac{\sigma-1}{\sigma}}+(1-\mu) S_{t}^{\frac{\sigma-1}{\sigma}}} \\
P_{o, t}=\alpha_{2} \mu \frac{Y_{t} O_{t}^{\frac{-1}{\sigma}}}{\mu O_{t}^{\frac{\sigma-1}{\sigma}}+(1-\mu) S_{t}^{\frac{\sigma-1}{\sigma}}}
\end{gathered}
$$

The combination of the above equilibrium conditions for both households and firms defines the competitive equilibrium. 
Next, we extend the competitive equilibrium to an optimal Ramsey problem by adding a government. We consider a benevolent government which chooses the optimal specific fossil fuel tax by solving a Ramsey problem to maximize social welfare. The government chooses the optimal tax such as the discounted utility is maximized subject to the first order conditions from the households and firms maximization problems. The environmental fiscal policy by the government, changes firms' profits such as,

$$
\Pi_{t}=Y_{t}-W_{t} L_{t}-R_{t} K_{t}-\left(P_{o, t}+\tau_{t}^{o}\right) O_{t}-P_{S, t} S_{t}
$$

where $\tau_{t}^{o}$ is a per unit tax on fossil fuel. This changes the behavior of the firm in choosing the optimal quantity of fossil fuels used as an input, as,

$$
P_{o, t}=\alpha_{2} \mu \frac{Y_{t} O_{t}^{\frac{-1}{\sigma}}}{\mu O_{t}^{\frac{\sigma-1}{\sigma}}+(1-\mu) S_{t}^{\frac{\sigma-1}{\sigma}}}-\tau_{t}^{o}
$$

We assume that all revenues from the fossil fuel tax are returned to the households as a lump-sum transfer. Hence, with a government implementing an environmental tax policy the household's budget constraint becomes,

$$
C_{t}+I_{t}=W_{t} L_{t}+R_{t} K_{t}+\tau_{t}^{o} O_{t}
$$

The benevolent government's maximization problem is given by,

$$
\max _{\left\{C_{t}, L_{t}, K_{t}, O_{t}, S_{t}, \tau_{t}^{o}\right\}} \sum_{t=0}^{\infty} \beta^{t}\left(\frac{C_{t}^{1-\gamma}}{1-\gamma}-\omega \frac{L_{t}^{1+\frac{1}{v}}}{1+\frac{1}{v}}\right)
$$

subject to (17), (18), (20), (21), (22), (24), (25), (7), (8), (6), (4) and (3). This maximization problem represents a government that, in choosing the optimal specific tax rate on fossil fuel, account for the impact on the tax on the optimal behavior by households and firms.

Table 3 shows the difference of steady states for the "laissez faire" and the Ramsey problem with respect to the steady state obtained for the centralized economy in order to study how far are both outcomes from the first-best. First, we find that differences in output are small. Output in the Ramsey problem is equal to that in the centralized economy, whereas in laissez faire output is a $0.31 \%$ lower. This is explained by the effect of pollution damage on aggregate productivity. On one hand, fossil fuel represents an input that has a positive contribution to output. On the other hand, consumption of fossil fuel produces emissions that have an harmful impact on aggregate productivity. Both opposing forces tend to compensate, resulting in small differences in output across scenarios. However, differences are larger for the rest of variables of the model. The Ramsey problem represents a second best policy and hence, equilibrium from the optimal tax policy is located between the social planner solution and the laissez faire outcome. Fossil fuel consumption, emissions and pollutants concentration are all about a $48 \%$ higher in the laissez faire scenario 
Table 3 Change in steady state with respect to the centralized economy

\begin{tabular}{lll}
\hline & Laissez Faire & Ramsey problem \\
\hline Output & -0.31 & 0.00 \\
Consumption & -3.42 & -0.41 \\
Fossil fuels & 47.79 & 6.86 \\
Renewable energy & -13.68 & -2.42 \\
Emissions & 47.77 & 7.10 \\
Pollutants concentration & 47.75 & 6.95 \\
Social Welfare & -0.47 & -0.07 \\
\hline
\end{tabular}

Note: Percentage difference in the steady state for each variable in both scenarios with respect to the steady state in the centralized economy

compared to the centralized outcome where the negative externality is fully internalized. Additionally, the consumption of renewable energy is around 14\% lower in laissez faire, as it is optimal for the social planner to increase the use of clean energy and reduce the use of fossil fuels. Although the impact on output is small, consumption is found to be a $3.4 \%$ lower in laissez faire, as a fraction of output is forgone due the climate damages, reducing the number of resources that can be devoted to consumption activities. Results from the Ramsey problem show that fossil fuel, emissions and pollutants concentration are around a 7\% higher, whereas consumption of renewable energy is a $-2.4 \%$ lower, compared to the centralized outcome. These differences sharply contrast with the outcome in the laissez faire scenario, indicating that the second best policy success in achieving energy transition by reducing the use of fossil fuels and increasing the renewable energies. All these results lead to a consumption a mere $0.4 \%$ lower compared to the centralized outcome for an equivalent level of output. Finally, with the benchmark calibration of the model social welfare in laissez faire is a $0.47 \%$ lower than in the first-best, whereas welfare is only a $0.07 \%$ lower in the Ramsey problem, indicating that this second-best policy is highly effective in correcting the negative effects of the environmental externality and able to almost achieve the centralized economy outcome. As the damage parameter increases, differences across the scenarios also increase.

\section{Concluding remarks}

This paper studies how the energy mix of renewable versus non-renewable energy sources is affected by technological shocks, and their implications for energy transition, carbon emissions, and the environment. Our starting evidence is that pollutant emissions varies widely depending on the energy source, and hence, alternative technological and price shocks have different effects on the environment depending on how they change the energy mix. The paper investigates those links using an E-DSGE model where final good sector productivity is negatively affected by pollutant emissions. The model uses a three factor production function: capital, labor, and energy, where two energy sources, fossil fuel and renewable energy, are considered. 
The summary of the main results of the paper are the following. First, energy consumption and emissions are procyclical, but emissions per unit of output are countercyclical, consistent with empirical evidence. This is a direct consequence of the decline in energy intensity as economic activity expands. We find that a neutral technological shock provokes an expansion of the economic activity, a higher energy consumption, increasing both fossil fuels and renewable energy consumption, and generates more emissions, resulting in a harmful impact on the environment. Second, an energy efficiency shock provokes a rebound effect above $100 \%$ (the socalled backfire effect), resulting in an increase in emissions, indicating that energy efficiency environmental policies must include additional instruments to avoid nonanticipated negative effects on the environment. By contrast, emissions are reduced in the case of an emission efficiency technological improvement, and in the case of an increase in the price of the "dirty" energy, although the transmission mechanisms are different. The emission efficiency technological shock reduces carbon emissions but also increases energy consumption and output. As pointed out by Acemoglu et al. (2012), if "dirty" and "clean" energy are sufficiently substitutable, then there is room for implementing directed technical change policies under alternative environmental policies to redirect technical change to renewable energy sources and reduce environmental damage.

In our theoretical framework, emissions are generated by the use of fossil fuel in the energy production activity, where renewable do not produce any externality. As fossil fuel consumption increases, the pollution externality cost also increases, reducing productivity. This makes the use of "dirty" energy more expensive. The model is solved for a decentralized economy in which a benevolent government solve a Ramsey problem and chooses an optimal specific tax on fossil fuels to maximize social welfare. The specific tax on fossil fuel provokes a substitution of fossil fuels energy by renewable energy, resulting in a decline in the level of emissions. We found that the second-best policy resulted from the Ramsey problem is able to shift the competitive equilibrium with no internalization of the environmental externality to an equilibrium close to the first-best where welfare losses are small compared to the laissez faire scenario.

Funding Open Access funding provided thanks to the CRUE-CSIC agreement with Springer Nature. Funding for open access charge: Universidad de Málaga/CBUA.

Open Access This article is licensed under a Creative Commons Attribution 4.0 International License, which permits use, sharing, adaptation, distribution and reproduction in any medium or format, as long as you give appropriate credit to the original author(s) and the source, provide a link to the Creative Commons licence, and indicate if changes were made. The images or other third party material in this article are included in the article's Creative Commons licence, unless indicated otherwise in a credit line to the material. If material is not included in the article's Creative Commons licence and your intended use is not permitted by statutory regulation or exceeds the permitted use, you will need to obtain permission directly from the copyright holder. To view a copy of this licence, visit http://creativecommons.org/licen ses/by/4.0/. 


\section{References}

Acemoglu D, Aghion P, Bursztyn L, Hemous D (2012) The environment and directed technical change. Am Econ Rev 102(1):131-166

Angelopoulos K, Economides G, Philippopoulos A (2010) What is the best environmental policy? Taxes, permits and rules under economicand environmental uncertainty, DEOS Working Papers 1014. Athens University of Economics and Business, Athens

Angelopoulos K, Economides G, Philippopoulos A (2013) First- and second-best allocations under economic and environmental uncertainty. Internat Tax Pub Finance 20:360-380

Annicchiarico B, Di Dio F (2015) Environmental policy and macroeconomic dynamics in a new Keynesian model. J Environ Econ Manag 69:1-21

Atalla T, Blazquez J, Hunt LC, Manzano B (2017) Prices versus policy: an analysis of the drivers of the primary fossil fuel mix. Energy Policy 106:546

Balke NS, Brown SPA (2018) Oil supply shocks and the U.S. economy: An estimated DSGE model. Energy Policy 116:357-372

Bjørnland HC, Larsen VH (2016) Oil and macroeconomic (in)stability. Norges Bank Working Paper 2016/02

De Miguel C, Manzano B, Martín-Moreno JM (2003) Oil price shocks and aggregate fluctuations. Energy J 24(2):47-61

Evgenidis A, Hamano M, Vermeulen WN (2020) Economic consequences of follow-up disasters: lessons from the 2011 Great East Japan Earthquake. TCER Working Paper E-152

Fischer C, Springborn M (2011) Emissions targets and the real business cycle: intensity targets versus caps or Taxes. J Environ Econ Manag 62:352-366

Frondel M, Peters J, Vance C (2012) Heterogeneity in the rebound effect: further evidence for Germany. Energy Econ 34(2):461-467

Gillingham K, Rapson D, Wagner G (2016) The rebound effect and energy efficiency policy. Rev Environ Econ Policy 10(1):68-88

Golosov M, Hassler J, Krusell P, Tsyvinski A (2014) Optimal taxes on fossil fue in general equilibrium. Econometrica 82(1):41-88

Heutel G (2012) How should environmental policy respond to business cycles? Optimal policy under persistent productivity shocks. Rev Econ Dyn 15(2):244-264

John A, Pecchenino R (1994) An overlapping generations model of growth and the environment. Econ J 104(427):1393-1410

Jones LE, Manuelli RE (1995) Growth and the effects of inflation. J Econ Dyn Control 19:1405-1428

Kim IM, Loungani P (1992) The role of energy in real business cycle models. J Monetary Econ 29(2):173-189

Newell R, Jaffe A, Stavins R (1999) The induced innovation hypothesis and energy-saving technological change. Q J Econ 114:941-975

Nordhaus W (2007) To tax or not to tax: the case for a carbon tax. Rev Environ Econ Policy 1(1):26-44

Nordhaus W (2008) A question of balance: weighing the options on global warming policies. Yale University Press, New Haven and London

Punzi MT (2019) The impact of energy price uncertainty on macroeconomic variables. Energy Policy 129:1306-1319

Rotemberg J, Woodford M (1996) Imperfect competition and the effects of energy price increases on economic activity. J Money Credit Bank 28(4):549-577

Small K, Van Dender K (2007) Fuel efficiency motor vehicle travel: the declining rebound effect. Energy J 28:25-51

Sorrell S (2009) Jevons' Paradox revisited the evidence for backfire from improved energy efficiency. Energy Policy 37:1456-1469

Stokey N (1998) Are there limits to growth? Internat Econ Rev 39(1):1-31

Smets F, Wouters R (2007) Shocks and frictions in US business cycles: a Bayesian DSGE approach. Am Econ Rev 97:586-606

Tahvonen O, Salo S (2001) Economic growth and transitions between renewable and nonrenewable energy sources. Eur Econ Rev 45:1379-1398 
World Bank12 (2012) Inclusive green growth: the pathway to sustainable development. World Bank, Washington

Publisher's Note Springer Nature remains neutral with regard to jurisdictional claims in published maps and institutional affiliations. 